\title{
PERCEPÇÃO DE NOVOS TERRITÓRIOS RURAIS: A IDENTIDADE PROPOSTA POR INDIVÍDUOS ASSENTADOS
}

\author{
Magdalen Julie Marques Machado Caetano ${ }^{1}$ \\ Nara Rejane Zamberlan dos Santos ${ }^{2}$
}

\section{RESUMO}

$\mathrm{Na}$ constante luta pela terra, uma parcela segregada da população encontra nos movimentos sociais uma forma de buscar condições de sobrevivência individual e coletiva. Porém, apenas a posse da terra não permite em curto espaço de tempo, o estabelecimento de unidades produtivas que oportunizem o resgate da dignidade e imponha uma qualidade de vida. Com o objetivo de caracterizar os indivíduos assentados e analisara percepção das formas de apropriação e planejamento dos lotes na atualidade e, em projeção futura, bem como identificar a importância dada ao elemento arbóreo como parte integrante das propriedades, foi desenvolvida a presente pesquisa junto ao Assentamento Itaguaçú, no interior do município de São Gabriel, RS. Metodologicamente, caracteriza-se como uma pesquisa de corte qualiquantitativo. A coleta de dados se deu através de entrevistas apoiada em instrumento semiestruturado. $O$ estudo permitiu a leitura de uma imagem social e produtiva em relação ao futuro. Concluiu-se que a luta destes sujeitos é pela constituição de um local digno para morar, produzir e conviver socialmente, porém entraves como a falta de infraestrutura, assistência técnica e crédito se constituem em obstáculos para o aperfeiçoamento das práticas produtivas e um instrumento ainda inacessível na obtenção de seus propósitos de luta política.

Palavras-chave: movimentos sociais, planejamento, produção, sujeito social, vegetação.

\section{PERCEPTION OF NEW TERRITORIES RURAL: IDENTIFY PROPOSAL FOR SETTLED INDIVIDUALS}

\begin{abstract}
In the constant struggle for land, a segregated population parcel finds in social movements, a way to seek conditions for individual and collective survival. Nevertheless, land ownership alone does not allow, in a short term, the establishment of productive units that will create opportunities for dignity restoration and impose some life quality. Thus, aiming to characterize the settled individuals and analyze the perception of the ways of land parcels appropriation and planning

${ }^{1}$ Graduada em Engenharia Florestal (UNIPAMPA - São Gabriel).Professora do Centro de Educação Tecnológica do Amazonas. E-mail: magdalenjuliemmc@gmail.com

${ }^{2}$ Doutora em Engenharia Florestal (UFSM). Professora Adjunta UFSM. Professora Associada Unipampa-São Gabriel. E-mail: narazamberlan@gmail.com
\end{abstract}


nowadays and, in a projected future as well as to identify the importance given to the arboreal component as part of the properties, this study was carried out at Itaguaçú Settlement in the city of São Gabriel, RS. The used methodology defines the study as a qualitative and quantitative research. The data collecting was performed through interviews based on a semi-structured instrument. The study allowed the reading of a social and productive image for the future. It was found that the struggle of these individuals is to establish a dignified place for living, producing and socially relate with each other. However, barriers like the lack of adequate infrastructure, technical assistance and financial credit are obstacles for the betterment of the productive practices and, an inaccessible instrument to obtain their purposes in political struggles.

Keywords: social movements, planning, production, social subject, vegetation.

\section{INTRODUÇÃO}

A questão agrária acompanha a própria história brasileira e se configura na luta pela ocupação da terra enquanto espaço vivido e produtivo, bem como pelo aumento da concentração fundiária, fruto das desigualdades socioeconômicas.

Para Miralha (2006), a importância da reforma agrária na atualidade recai na sua relevância social, como uma política de distribuição de renda e de inclusão, proporcionando a oportunidade de uma grande parte de pessoas, das periferias urbanas e, excluídos do mercado de trabalho, voltarem para o campo, agora com as condições para produzir de maneira viável, resgatando assim sua dignidade.

O acesso à terra do ponto de vista econômico é um instrumento de fortalecimento da agricultura familiar: politicamente, é fundamental para a proposição de um novo ordenamento territorial ao país e o avanço da regularização fundiária, que garantem soberania nacional e segurança jurídica para a produção, socialmente, se traduz em uma política de combate à pobreza e de ampliação de direitos, como o acesso à moradia, alimentação, saúde, educação e renda, e sob o aspecto ambiental, as políticas de reforma agrária e ordenamento fundiário abrem caminho para uma produção agrícola diversificada e capaz de ajudar a preservar as riquezas naturais do país (INCRA, 2010).

A criação dos assentamentos, conforme Ramalho (2002) possibilitou focar as estratégias de reprodução familiar e de sustento no próprio lote às populações de baixa escolaridade e com dificuldades de inserção no mercado rural/agrícola, possibilitando, mesmo que de forma precária, o acesso à moradia, escola e saúde, criando-se assim novos sujeitos sociais e resgatando a dignidade de populações, historicamente, excluídas.

O termo assentamento está relacionado, segundo Bergamasco et al. (1997), no contexto da reforma agrária a um espaço preciso em que uma população será instalada e, portanto, isto significa uma transformação do espaço físico, objetivando a sua exploração agrícola. $O$ ato de assentar estes indivíduos envolve não somente a sua fixação, mas o estabelecimento das condições de produção e sustento, além da construção de uma vida familiar e comunitária.

A luta para a conquista da terra é árdua, mas o processo de territorialização não se encerra até que se crie a infraestrutura necessária e se organize social e produtivamente (TSUKAMOTO; ASARI, 2003).

Tendo como referência as dificuldades impostas aos assentados nos primeiros anos, referidas largamente na literatura, nos seu processo de adaptação, organização e produção, para lhes conferir condições dignas de sobrevivência, o 
presente trabalho buscou através de levantamento de campo: - caracterizar os atores envolvidos na ocupação do Assentamento Itaguaçú, São Gabriel, RS; identificar as formas de apropriação e desenvolvimento dos lotes; - reconhecer a importância de espécies arbóreas no contexto do assentamento; e,- perceber a projeção destes espaços no imaginário dos novos atores rurais.

\section{REFERENCIAL TEÓRICO}

\subsection{REFORMA AGRÁRIA}

Segundo a Lei $n^{\circ} 8.629$, de 25 de fevereiro de 1993 (BRASIL, 1993), sobre os dispositivos constitucionais relativos ao conceito geral de reforma agrária, previsto na Constituição Federal de 1988, afirma-se que é o sistema que serve para regular e promover a divisão dita justa de terras em um estado.

O Brasil como detentor de altos índices de concentração fundiária, passa, segundo Mello e Sulzbacher (2013), a partir da década de 1930 a assumir para si a atribuição de ocupar áreas, expandir a fronteira agrícola e desenvolver o meio rural. Porém, para Souza e Pereira (2008) é preciso um avanço no processo de reforma agrária para a superação da desigualdade de renda e distribuição de propriedade.

De acordo com Freire (2001), a reforma agrária deve ser um processo de desenvolvimento do qual resulte, necessariamente, a modernização do campo, como da agricultura, enquanto para Ranieri,

é um termo utilizado para descrever uma série de ações que têm como base a reordenação fundiária como mecanismo de acesso à terra e aos meios de produção agrícola aos trabalhadores rurais sem terra ou com pouca terra(RANIERI, 2003, p. 37).

A partir do Decreto no 1.110, de 9 de julho de 1970 (Brasil, 1970) foi criado o Instituto Nacional de Colonização e Reforma Agrária (INCRA), autarquia federal que possui a missão prioritária de realizar a reforma agrária no país, manter o cadastro nacional de imóveis rurais e administrar as terras públicas da União. O INCRA incorporou entre suas prioridades a implantação de um modelo de assentamentos, além de qualificação, acesso a uma infraestrutura básica, assessoria técnica e consultorias gratuitas aos assentados para que possam aproveitar da melhor maneira possível os recursos das terras em que passarem a habitar e produzir.

A Reforma Agrária no Brasil se dá, basicamente, da seguinte forma: a União realiza a compra ou desapropriação de latifúndios particulares considerados improdutivos e sob a figura do INCRA, distribui e loteia essas terras às famílias as quais recebem esses lotes (REFORMA AGRÁRIA NO BRASIL, 2014).

O sucesso do assentamento, na opinião de Sparovek e Maule (2003) inicia pela seleção de regiões aptas para a reforma agrária, o que demanda ferramentas de escala local possíveis de análise das condicionantes do meio físico e regional de maneira, a permitir a correta escolha da área para o desenvolvimento do assentamento.

Os latifúndios desapropriados para assentamentos, normalmente, possuem poucas benfeitorias e infraestrutura, como saneamento, energia elétrica, acesso à cultura e lazer. Por isso, as famílias assentadas seguem organizadas e realizam novas lutas para conquistarem estes direitos básicos. 


\subsection{A FORMAÇÃO DOS ASSENTAMENTOS E O PAPEL DA EXTENSÃO RURAL}

A expressão "assentamento" é utilizada para identificar não apenas uma área de terra no âmbito dos processos de reforma agrária, destinada à produção agropecuária e ou extrativista. Além disso, também é um espaço heterogêneo de grupos sociais constituídos por famílias camponesas, que adquire vida depois de desapropriado ou adquirido pelos governos federal e/ou estaduais, com o fim de cumprir as disposições constitucionais e legais relativas à Reforma Agrária (CARVALHO, 1999).

Bergamasco e Norder (1996, p. 7) colocam que:

de maneira genérica, os assentamentos rurais podem ser definidos como a criação de novas unidades de produção agrícola, por meio de políticas governamentais visando o reordenamento do uso da terra, em benefício de trabalhadores rurais sem terra ou com pouca terra.

Para Bergamasco et al. (1997) o termo assentamento, no contexto da reforma agrária brasileira está relacionado a um espaço preciso em que uma população será instalada é, portanto, uma transformação do espaço físico, cujo objetivo é a sua exploração agrícola.

Conforme Santalucia e Hegedus (2005, p.98),

os assentamentos rurais no Brasil, em sua grande maioria, são constituídos por lotes individuais, com área estimada a partir da definição de módulo regional, ficando as famílias praticamente sozinhas para se desenvolverem em uma situação econômica desfavorável de escassos recursos e tendência de queda dos preços agrícolas.

A organização espacial de um assentamento é formada pela divisão de lotes destinados às famílias, ou seja, cada família é contemplada com um lote. Conforme Ramirez et al. (2013) a organização dos espaços dos lotes está associado ao ambiente socioeconômico gerado pelos assentamentos e suas famílias.

Quando os assentados (as famílias) chegam ao lote eles passam a vivenciar algo desconhecido, novo, onde eles terão que aprender com seus erros ao usar a terra, produzir, conquistar e organizar. Os assentados são de outras regiões e a troca de saberes com os outros assentados e com os técnicos extensionistas é fundamental para essa nova experiência. Normalmente, segundo Xavier (2013), no assentamento há uma convivência entre as pessoas nas atividades laborais, e também na esfera comunitária, com espaço político da participação nas associações e no lazer.

Segundo Martins et al. (2011), por meio do planejamento, iniciam-se as etapas de organização do lote e, a partir da construção de um local de moradia, torna-se possível a mudança da família para "cima do lote", ainda que em um abrigo provisório.

As famílias, em seus primeiros anos sobre o lote, organizam sua moradia e todo o espaço do mesmo, bem como, o que irão produzir para suprir suas necessidades. Todo este planejamento é pensado devido à preocupação futura com os seus lotes. Para Xavier (2013), o cotidiano das famílias assentadas envolve uma série de trabalhos na agricultura, no cuidado com animais, nos afazeres domésticos, que resultam em saberes de experiências que são mobilizados, mas também são desenvolvidas atividades comunitárias concernentes à cultura, ao lazer, à educação, 
à religião.

Diante desta nova realidade que se impõe no cenário nacional há a necessidade de um novo profissional para os quadros da extensão rural. Neste sentido Caporal (2009) aponta o perfil desejado deste profissional: ter visão holística e sistemática voltada à sustentabilidade, ser articulador e canalizador, ter capacidade de liderança, demonstrar e praticar posturas participativas, capacidade da análise e síntese e ter aptidão para o planejamento e a ação planejada. Segundo o autor, os processos de formação dos novos extensionistas deveriam congregar conteúdo e abordagens transdisciplinares, de modo incorporar uma compreensão dos processos sociais, políticos e econômicos.

Abramovay (1997) apud Silva e Araújo (2008) sintetiza ideias a respeito de um novo modelo contemporâneo de serviço público de assessoria rural o qual deve inserir sua ação em uma luta mais ampla como a busca de cidadania, do desenvolvimento sustentável, da participação, livre organização e ampliação do acesso ao conhecimento, bem como deve despertar o conjunto das energias locais capazes de valorizar o campo como espaço propício na luta contra a exclusão social. Assim, o trabalho da extensão rural não deve se restringir apenas àquele público capaz de dar respostas de imediato, pois o público da extensão deve se definido como o conjunto dos participantes das múltiplas iniciativas destinadas à valorização do espaço e das oportunidades locais de geração de renda.

Porém, Silva (2014) pondera que:

O processo de transmissão do conhecimento técnico e de difusão da tecnologia para o meio rural é uma ação que apresenta uma dificuldade intrínseca e que, em função das características peculiares dos elementos envolvidos, pode resultar em insucesso. Deve-se entender, a princípio, que o homem rural e o técnico, pretenso detentor do conhecimento que tenciona difundir, apresentam ontogenias diferentes e distantes, e que, deste modo, realizam um acoplamento estrutural de difícil consolidação. Não se trata, aqui, de problemas de acolhida ou de relacionamento, muito pelo contrário. O que se verifica é que, em algumas situações, o conhecimento é repassado, mas não assimilado e empregado; a tecnologia é transferida, porém não adotada (SILVA, 2014, p.42).

Para Navarro (1999), as equipes extensionistas devem trabalhar em nível de comunidade com diagnóstico rural, lembrando que cada comunidade é diferente necessitando que o próprio homem rural atue como ator de sua própria mudança.

\subsection{ELEMENTO “ÁRVORE”: SEU PAPEL ESPACIAL E PRODUTIVO}

O Brasil é considerado pela sua diversidade representada pela variedade de formações vegetais e ecossistemas, que abrigam uma das floras mais diversificadas e exuberantes do planeta. As árvores são plantas com caules e ramos lenhosos. Em geral, a maioria apresenta um tronco lenhoso único e ramos formando uma copa.

A presença de árvores traz benefícios diretos e indiretos, como o controle da erosão, manutenção da fertilidade do solo e proporciona o aumento da biodiversidade (ARANA; ALMIRANTE, 2007).

De acordo com Grey e Deneke (1978), citados por Milano e Dalcin (2000), a contribuição das árvores como protetoras contra a radiação solar é significativa, já que as árvores e outros vegetais refletem, absorvem e transmitem radiação e, por 
meio da fotossíntese, também fixam energia, influenciando nas condições ambientais.

As árvores são subutilizadas nas propriedades rurais. A arborização permite repovoar de forma ordenada áreas de pastagens a céu aberto, para proteger o rebanho dos extremos climáticos e ainda, obter serviços ambientais e diversificação de produtos florestais e pecuários (MONTOYA et al., 1994).

Áreas consideradas impróprias para a agricultura ou pastagens em estágio inicial de degradação, conforme o autor, também podem ser utilizadas e recuperadas por meio da introdução de arbóreas.

Mascaró e Mascaró (2005) afirmam que o vento influencia, significativamente, na ambiência dos espaços e, consequentemente, na sensação térmica dos usuários. A vegetação desempenha efeitos básicos sobre o vento, conforme Robinete (1972) citado por Mascaró e Mascaró (2005), como: canalização, deflexão, obstrução e filtragem.

O uso de barreiras quebra-ventos, segundo Volpe e Schoffel (2001), serve como anteparo e atenua a velocidade e turbulência do vento, proporcionando melhorias às condições ambientais através do controle do microclima da área protegida.

As árvores selecionadas para compor as barreiras quebra-vento devem ser resistentes aos ventos, às pragas e às doenças, além de terem raízes profundas, serem de rápido desenvolvimento e frondosas (perenifólias). No delineamento de barreiras quebra-vento, sua estrutura (porosidade, formato, largura, comprimento e altura) e distribuição espacial (orientação, espaçamento, configuração) devem ser claramente definidas para que se alcance o máximo de benefícios (VOLPE; SCHOFFEL, 2011).

Segundo Silva et al. (1998) as árvores constituem uma barreira, impedindo a formação de geadas. Essa proteção, segundo os autores, resulta em termos práticos, em pastagens verdes sob árvores durante o inverno.

Em relação às arbóreas frutíferas, Manica et al. (2007) salientam que as mesmas, além de embelezar a propriedade, exibem o seu verde intenso, folhagens, flores e frutos, proporcionando um microclima agradável, e harmonioso. As plantas frutíferas absorvem o excesso de água das chuvas, aumentam a microflora e criam um ambiente saudável, tranquilo, alegre, contribuindo para melhoria e manutenção da qualidade de vida deseus moradores.

A introdução de viveiros comunitários em assentamentos é defendida por Rodrigues et al. (2004) que os apontam como importante ferramenta nos planos de recuperação ambiental, além do caráter socioeconômico, pois podem reverter na geração de renda familiar conciliada ao conforto ambiental resultando em maior qualidade de vida às famílias assentadas.

\section{PROCEDIMENTOS METODOLÓGICOS}

O município de São Gabriel - RS, segundo dados do censo do Instituto Brasileiro de Geografia Estatística (IBGE, 2010) possui uma população de 60.425 habitantes e uma área territorial de $5.024 \mathrm{~km}^{2}$ (Figura 1) e localiza-se na Fronteira Oeste do estado Rio Grande do Sul, às margens da BR 290 (PREFEITURA MUNICIPAL DE SÃO GABRIEL, 2008; GOVERNO DO ESTADO DO RIO GRANDE DO SUL, 2012). 
Figura 1- Localização do município de São Gabriel, RS

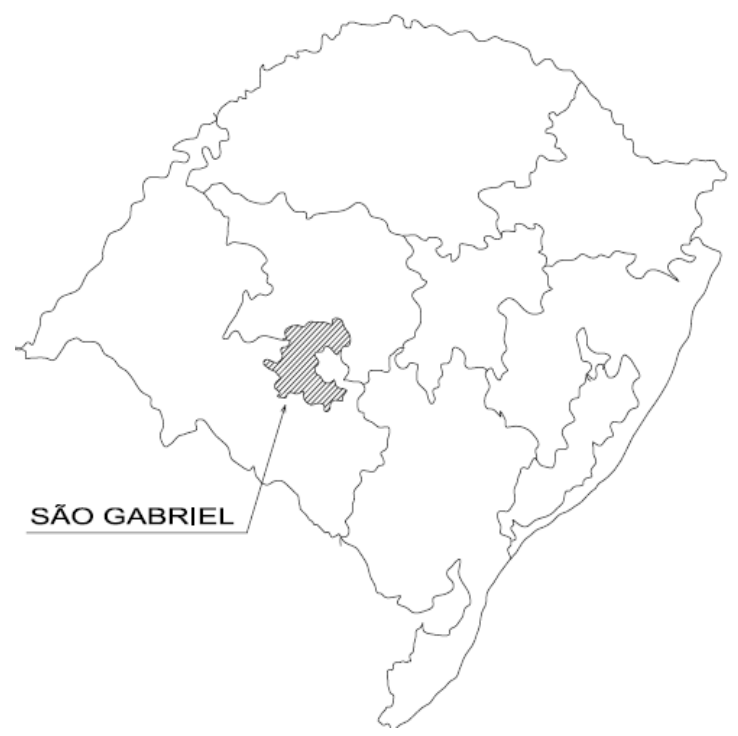

Desenho: Paulo Grapiglia

O Assentamento Itaguaçú, objeto do presente estudo situa-se na zona rural do município de São Gabriel, às margens da RS - 630 (Figura 2). Apresenta uma área total de 1996 hectares, sendo que cada lote possui uma área aproximada de 17 hectares.

Figura 2- Localização das principais vias de acesso ao município de São Gabriel, RS

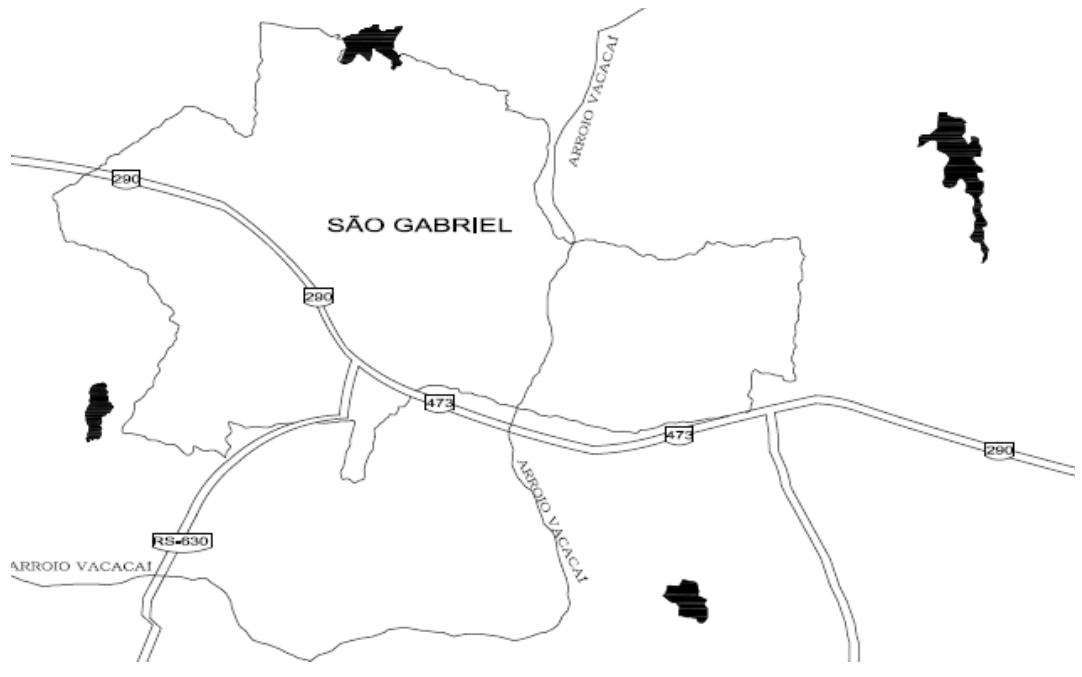

Desenho: Paulo Grapiglia 
A pesquisa foi realizada com famílias assentadas no Assentamento Itaguaçú, as quais se estabeleceram no período de 2008 a 2011. Embora com aproximadamente, noventa e nove famílias assentadas, conforme o INCRA (2011), apenas sete famílias participaram da pesquisa. Os motivos que levaram a estudar esta amostra foram a indicação realizada pela COPTEC (Cooperativa de Prestação de Serviços Técnicos), pelo interesse demonstrado pelos mesmos em participar e pela própria localização dos lotes em locais de fácil acesso, pois não existem vias demarcadas e em condições de trafegabilidade.

Como esses atores pertencem à categoria de assentados, estando assim já inseridos em um conjunto mais ou menos uniforme, segundo Crespo (1996), a amostra representativa da população, é do tipo aleatória simples sistematizada.

A pesquisa desenvolvida teve abordagem quali-quantitativa. Conforme Neves (1996), a abordagem quantitativa permite o redirecionamento das atividades durante o processo além da interação do pesquisador com os sujeitos da pesquisa. Também pode ser considerado um estudo de caso que, segundo Triviños (1987) tem por finalidade 0 aprofundamento da descrição de determinadas realidades.

A integração da pesquisa qualitativa e quantitativa para Goldenberg (2007) permite que se façam cruzamentos das conclusões de modo a ter maior confiança nos dados.

A pesquisa desenvolveu-se em quatro etapas:

$\mathrm{Na}$ primeira etapa ocorreram os contatos com a comunidade do Assentamento Itaguaçú através da COPTEC que presta a assistência técnica ao assentamento, juntamente com os líderes das comunidades dos assentamentos do município. Posteriormente, a pesquisa foi apresentada aos assentados, em uma reunião, no próprio assentamento, onde foi possível esclarecer os objetivos da mesma.

$\mathrm{Na}$ segunda etapa foram selecionadas sete famílias, totalizando vinte pessoas, interessadas em participar da pesquisa. Após (terceira etapa) foram aplicados questionários, tido como um roteiro de questões fechadas e abertas, caracterizando-se por uma entrevista semiestruturada. As questões fechadas foram utilizadas para obtenção de informações sócio demográficas das famílias, enquanto as abertas foram utilizadas para caracterizar a organização do lote e percepção dos mesmos em relação as condições encontradas e a projeção futura.

A partir da obtenção dos dados efetuou-se a tabulação e interpretação dos dados constituindo-se na quarta etapa.

\section{RESULTADOS E DISCUSSÃO}

Após os primeiros momentos de convívio com as famílias e a participação no cotidiano, de modo a dissipar alguma timidez e receio foram iniciadas as entrevistas com o propósito de identificar e caracterizar os vários sujeitos.

Em relação aos seus municípios de origem, identificou-se entrevistados naturais dos municípios de Cerro Largo, Roque Gonzales, São Luiz Gonzaga, Liberato Salzano, Caiçara, Santa Bárbara do Sul, Palmeiras das Missões, todos eles pertencentes a mesorregião Noroeste Rio-Grandense, do estado do Rio Grande do Sul, o que demonstra as diferenças em relação às culturas e hábitos entre a região de origem e a receptora,

O grau de parentesco é uma forma de organização social e os entrevistados conviviam em seus lotes com o padrão da família nuclear formada por graude parentesco do tipo: marido, esposa, filha, filho e neto. Dos entrevistados dez são do gênero feminino e dez masculino, sendo que a maioria das crianças 
presentes eram menores de nove anos, filhos e netos dos entrevistados, prevalecendo assentados com idade entre 20 a 39 anos e, apenas dois com idade superior a 60 anos.

Os assentados pesquisados possuem idade inferior aos dados demonstrados no trabalho desenvolvido por Bergamasco (1997), que apontou que $48,4 \%$ do total dos titulares dos lotes de assentamentos, no Brasil, possuí entre 36 e 57 anos, enquanto Fietz et al. (2010) em estudo em assentamento em Mato Grosso do Sul registraram a idade média de 43 anos.

Embora todos os adultos soubessem ler nenhum tinha ensino superior, prevalecendo à formação relativa ao fundamental incompleto. A identidade jovem dos assentados e de seus dependentes justifica a presença de cinco crianças ainda fora da escola. Trabalho realizado por Campos, Silveira e Caliari (2015) no Assentamento São Domingos dos Olhos D'Àgua, GO, identificaram que 98\% dos componentes de famílias pluriativas são alfabetizados, 35\% dos componentes dessas famílias alcançaram o ensino médio e não há pessoas vivendo abaixo do nível de pobreza.

Ainda sobre a caracterização dos entrevistados todos residem e trabalham no assentamento, desenvolvendo atividades nos seus lotes. A situação comprovada vem de encontro às observações de Oliveira (2007), ao se referir ao surgimento dos assentamentos para esses atores como um campo de possibilidades, que garante o trabalho, moradia e créditos. Nestes casos, conforme o autor, os assentamentos também podem ser vislumbrados como um ponto final relativo, pois, aquele ambiente pode ser visto como um espaço que possibilitará um salto para outro degrau socioeconômico.

A permanência dos assentados nos lotes revela o desejo destas famílias em se estabelecer e desenvolver práticas produtivas, pois estudos realizados por Aleixo (2007) demonstram a existência de outras situações como à venda do lote, entre outras, entendida como a comercialização mediante o pagamento em dinheiro, equipamentos, veículos e ou outras vantagens pessoas. Também neste sentido, Santa Lucia e Hegedus (2005) complementam que vários assentamentos no país apresentam problemas estruturais, deficiência de assistência técnica, evasão rural conduzindo a venda irregular de lotes.

Ainda nesta direção, Cruz e Santos (2011) comentam que a comercialização de posses de lotes é uma realidade que se faz presente nos espaços dos assentamentos e um fator importante para que se questionem as condições nas quais os sujeitos da Reforma Agrária estão se reproduzindo.

Em relação às moradias dos entrevistados, grande parte deles moram em casas feitas de madeira, e dentre estas, quatro possuem energia elétrica, confirmando Bergamasco (1997), que afirma que as casas de madeira são encontradas nos assentamentos na região Sul, enquanto as de alvenaria são mais comuns na região Sudeste.

Já em relação ao esgotamento sanitário, os dejetos são depositados em "fossas rudimentares", que são lançadas em cursos d'água ou, diretamente, no solo a céu aberto. Esse cenário sobre o esgotamento sanitário coloca em risco a saúde da população, em especial as crianças, bem como a proteção dos mananciais de água e a preservação do meio ambiente.

A água não advém do sistema público de saneamento, e sim, de poços e açudes e, em épocas de estiagem o abastecimento fica totalmente comprometido. Este fato foi presenciado no momento de coletas de dados da pesquisa quando acontecia o fenômeno da estiagem, sendo necessária a presença da Defesa Civil para o fornecimento de água para consumo. Nessa entrevista também foi notória a observação de que nenhuma família possui qualquer tipo de sistema de irrigação 
para a produção.

Sobre a opinião dos mesmos sobre as condições como ocorrem os deslocamentos do Assentamento Itaguaçú ao centro da cidade de São Gabriel, todos consideram de difícil acesso, e mencionaram que a maior dificuldade é a própria extensão do assentamento, pois, normalmente, eles necessitam se deslocar, em média, até $10 \mathrm{~km}$ até a parada do ônibus coletivo e esse acesso é feito à pé, à cavalo, de bicicleta, com motocicleta ou de carroça, pois a frequência em que necessitam o deslocamento à sede do município é variável com as necessidades, porém, normalmente, é de uma a três vezes ao mês, conforme Quadro 1.

Quadro 1- Motivação e meios de deslocamento dos entrevistados do Assentamento Itaguaçú, São Gabriel, RS.

\begin{tabular}{|c|c|c|c|c|c|c|}
\hline \multirow[t]{2}{*}{ Entrevistado } & \multirow[t]{2}{*}{ Motivação } & \multirow{2}{*}{$\begin{array}{c}\text { Meio de } \\
\text { deslocamento }\end{array}$} & \multicolumn{4}{|c|}{ Período } \\
\hline & & & $\begin{array}{l}\text { Jan. } \\
2012\end{array}$ & $\begin{array}{l}\text { Fev. } \\
2012\end{array}$ & $\begin{array}{l}\text { Mar. } \\
2012\end{array}$ & $\begin{array}{l}\text { Abril } \\
2012\end{array}$ \\
\hline 01 & Saúde & Bicicleta & $x x x$ & $x x$ & $x$ & - \\
\hline 02 & Compras & Motocicleta & - & $x$ & $x x$ & $x$ \\
\hline 03 & Vendas & Bicicleta & - & - & $x$ & - \\
\hline 04 & Saúde & Cavalo & - & $x$ & $x x x$ & - \\
\hline 05 & Diversas* $^{*}$ & A pé & $x$ & - & $x$ & $x x$ \\
\hline 06 & Lazer & Bicicleta & - & $x$ & - & - \\
\hline 07 & Viagem & A pé & - & $x$ & - & $x$ \\
\hline 08 & Compras & Motocicleta & $x$ & - & $x$ & $x$ \\
\hline 09 & Compras & Carroça & - & $x$ & $x$ & - \\
\hline 10 & Saúde & A pé & - & - & - & $\mathrm{XXX}$ \\
\hline 11 & Diversas* $^{\star}$ & Bicicleta & $x X$ & - & - & $x$ \\
\hline 12 & Saúde & Cavalo & - & $x$ & - & - \\
\hline 13 & Compras & Bicicleta & $x$ & $x$ & $x$ & $x$ \\
\hline 14 & Viagem & A pé & - & - & $x$ & - \\
\hline 15 & Saúde & Carroça & - & $x$ & $\mathrm{XXX}$ & - \\
\hline 16 & Diversas* $^{*}$ & Bicicleta & $x$ & - & $x x$ & - \\
\hline 17 & Diversas* $^{\star}$ & Cavalo & - & $x$ & $x$ & $x$ \\
\hline 18 & Saúde & A pé & - & $x x$ & - & $x$ \\
\hline 19 & Compras & A pé & $x$ & - & $x$ & $x x$ \\
\hline 20 & Compras & A pé & - & $x$ & $x$ & $x$ \\
\hline
\end{tabular}

*diversas= compras, saúde, pagamentos, documentação, entre outras;

$\mathrm{x}=$ número de deslocamentos

Fonte: dados de pesquisa

A dificuldade de deslocamento dos assentados é relatada por Oliveira (2007), em pesquisa nos arredores do Distrito Federal, pois segundo o autor é na cidade que eles costumam comprar os seus bens de consumo imediato, além de buscar o que necessitam.

As condições impostas pela localização, distâncias no interior do assentamento e em relação às estradas e paradas de ônibus, impõem dificuldades 
diárias aos estudantes, ao transporte de gêneros e as necessidades oriundas da própria saúde dos cidadãos. Neste sentido, Turnes (2004) ressalta que o desenvolvimento local deva ser o promotor da qualidade de vida para as pessoas que vivem no território, sendo o atendimento a saúde uma de suas dimensões intrínsecas.

Dentre os bens pertencentes às famílias, $60 \%$ possui fogão a lenha e a gás, televisão e geladeira, $50 \%$ rádio e $30 \%$ máquina de lavar roupa e liquidificador.

Em pesquisa já referida de Campos, Silveira e Caliari (2015), 100\% dos assentados têm acesso à luz elétrica e possuem geladeira.

Em relação ao rádio, Fagotti (2012) aponta como o meio de comunicação privilegiado em sociedades agrícolas ou rurais, sendo em alguns casos o único veículo de informação de agricultores, caracterizando-se pelo baixo custo e fácil acesso.

Quantos aos meios de comunicação não foi constatada a presença de telefones fixos, porém $70 \%$ possuem telefone celular, embora ressaltem a dificuldade de serviço devido à falta de sinal na região.

Em relação às ferramentas agrícolas disponíveis para o uso em suas atividades, mencionaram: enxadas, foices, facões, capinadeira, arado, pás, cavadeiras, machados, plantadeira manual (pica-pau), serrotes e machados, demonstrando a precariedade de equipamentos, para os cultivos, não somente de subsistência, mas que lhes permitam novas conquistas em termos de uso e produção da terra conquistada.

Como fazer frente a produtores que instituíram avanços tecnológicos em suas propriedades, com a implantação de novas máquinas e equipamentos de última geração, com parcos instrumentos de trabalho? Mais uma vez fica evidente a necessidade de apoio técnico a estes assentados e, principalmente, linhas de crédito, que lhes permitam a aquisição de equipamentos e insumos básicos para tornar estas terras produtivas e impor uma qualidade de vida aos atores envolvidos.

Em contrapartida, Strachulski e Floriani (2014)defendem que a incorporação de maquinário agrícola e de alguns insumos pode diminuir a intensidade das relações e dos contatos sociais entre os vizinhos.

Um dos temas da entrevista referia-se a organização do lote, quando foi possível aos assentados transmitir suas sensações e perspectivas.

À pergunta: Como era a terra do lote quando chegaram aqui? Os entrevistados responderam citando as seguintes expressões: "campo bruto, pastagem, campo, macegão, grama, cupim, tristeza, péssimo, macega, desespero para ir embora, terra boa".

Embora representando a realização de um sonho "de ter e estar na terra" à chegada ao lote representa um desafio, pois não possuem moradia e nenhuma produção, e muitas vezes sem acesso a energia elétrica e água.

No processo de organização dos lotes, os assentados, ao seu tempo, executam tarefas relativas à implantação de benfeitorias, cultivos agrícolas e introdução da pecuária, conforme Quadro 2. Percebe-se a preocupação dos mesmos em construir suas moradas mesmo que, inicialmente, de forma provisória. O direito à moradia é um dos núcleos que possibilita a consecução da dignidade da pessoa humana, razão pela qual deve ser implementado em todos os níveis (RANGEL; SILVA, 2009). 
Quadro 2- Etapas de organização dos lotes dos entrevistados do Assentamento Itaguaçú, São Gabriel/RS.

\begin{tabular}{|c|c|c|c|}
\hline & \multicolumn{3}{|c|}{ Etapas da organização dos lotes } \\
\hline Família & $1^{a}$ & $2^{a}$ & $3^{\mathrm{a}}$ \\
\hline 1 & Plantio de árvores & $\begin{array}{l}\text { Construção de } \\
\text { moradia provisória }\end{array}$ & - \\
\hline 2 & $\begin{array}{l}\text { Construção da } \\
\text { casa }\end{array}$ & $\begin{array}{l}\text { Cercamento do } \\
\text { lote }\end{array}$ & Formação de potreiro \\
\hline 3 & Plantio de árvores & $\begin{array}{l}\text { Construção da } \\
\text { casa }\end{array}$ & Preparação do solo. \\
\hline 4 & $\begin{array}{l}\text { Construção de } \\
\text { moradia } \\
\text { provisória }\end{array}$ & $\begin{array}{l}\text { Preparação do } \\
\text { solo para plantio } \\
\text { de milho }\end{array}$ & $\begin{array}{l}\text { Preparação do solo } \\
\text { para futuros plantios }\end{array}$ \\
\hline 5 & Roçada & $\begin{array}{l}\text { Construção da } \\
\text { casa }\end{array}$ & $\begin{array}{l}\text { Plantio de cinamomos, } \\
\text { implantação de horta }\end{array}$ \\
\hline 6 & $\begin{array}{l}\text { Construção da } \\
\text { casa }\end{array}$ & $\begin{array}{l}\text { Implantação de } \\
\text { horta }\end{array}$ & Plantios em geral. \\
\hline 7 & $\begin{array}{l}\text { Construção da } \\
\text { casa }\end{array}$ & Plantios & - \\
\hline
\end{tabular}

Fonte: dados de pesquisa

Dentro do processo de organização do lote, os assentados utilizaram alguns critérios para o plantio de árvores objetivando a produção de sombra nos lotes e a função de quebra-vento. Porém, o processo de organização foi acontecendo, conforme a necessidade do grupo, e a produção voltada apenas para o consumo próprio.

Os entrevistados mencionaram as melhorias já realizadas, dentre as quais: atividades ligadas à produção agrícola como adubação e preparo do solo para o plantio de hortaliças, árvores e outras espécies sazonais. Ainda, houve o cercamento dos lotes para a criação de animais e melhorias dos domicílios.

Quando indagados se achavam importante morar no campo e o porquê, todos se manifestaram positivamente e, em nenhum instante foi mencionada a infelicidade de morar naquelas condições, especificamente, em um assentamento.

A respeito disso se ressaltam frases como:

É muito importante morar no campo, é uma necessidade, por que 0 alimento da cidade sai da agricultura familiar (Entrevistado 3).

No campo cria as coisas sadias: galinha, carne de primeira, banha, mas em certas ocasiões é difícil (Entrevistado 1).

Morar no campo é bom para criar os filhos, é melhor que na cidade(Entrevistado 5).

Legal, se tira a própria comida, próprio sustento (Entrevistado 2).

Sim, situação tranquila (Entrevistado 4).

É importante observar que, dentre as famílias entrevistadas, quatro se consideram moradores do campo e os demais responderam se intitulam agricultores ou pequenos agricultores. Conforme Parecer 36/2001 sobre as Diretrizes Operacionais da Educação Básica nas Escolas do Campo apresentados em Conselho Escolar e Educação do Campo (Brasil, 2006), o campo é mais do que 
um perímetro não-urbano, é um campo de possibilidades que dinamizam a ligação dos seres humanos com a própria produção das condições da existência social e com as realizações da sociedade humana.

$\mathrm{Na}$ organização do lote e na produção no mesmo, geralmente as tarefas são divididas, dadas a diversidade de atividades, típicas de pequenas propriedades rurais.

A área hoje referente ao Assentamento Itaguaçú, antigamente era um complexo de três fazendas, sedes e casas para os proprietários e seus empregados. Nessas áreas existiam árvores para sombreamento e espécies frutíferas, enquanto o restante das fazendas servia como áreas de produção agrícola e pecuária. Hoje, parte desta extensão de terras são áreas comuns ao assentamento, local onde a comunidade se encontra para reuniões e outros tipos de eventos.

Para Strachulski e Floriani (2014), a partir da leitura das formas da paisagem é possível entender como se estruturam os sistemas agrários e produtivos.

Quando Ihes foi perguntado se já existiam árvores nos lotes quando ali chegaram, apenas um entrevistado respondeu afirmativamente, enquanto os demais responderam, negativamente:

Não tinha um pé de nada(Entrevistado 7).

Só tinha 2 ou 3 pé de eucalipto (Entrevistado 3).

A partir desta constatação demonstraram motivação para a realização de plantios com espécies arbóreas, tanto ornamentais como frutíferas, embora relatos dêem conta de problemas constantes como à estiagem, a formiga, além do registro de um incêndio que dizimou as plantações.

Em relação à possibilidade de conseguirem mudas, houve unanimidade em relação às dificuldades pelos seguintes motivos: alto preço e a distância dos viveiros. Ainda discorreram que era necessário deslocar-se a longas distâncias nas áreas de mata nativa para a coleta de sementes para a produção de suas próprias mudas.

Dada às dificuldades típicas de áreas de assentamentos se buscou levantar, em especial do local de estudo, as principais dificuldades vivenciadas. A intensidade do vento, retardando o desenvolvimento das mudas e, a consequente perda de umidade do solo; a falta de sombreamento nas residências as quais permanecem expostas a ação do sol no período de verão; o combate incessante às formigas e a presença de áreas erodidas foram destacadas nas respostas.

A falta de água, fator extremamente significante para a produção e consumo foi, exaustivamente, apontada, somado à precariedade dos acessos.

O distanciamento da orientação técnica e a falta de recursos financeiros se constituíram numa constante nos relatos apresentados.

Porém, uma das indagações da pesquisa era perceber como o assentado projeta seu lote para o futuro. Este foi um momento de muito entusiasmo, refletindo a esperança destas famílias que se referiam aos lotes

(...) com diversidade de árvores frutíferas, árvores de sombra, rebanho de vacas leiteiras, ovelhas e outros animais, bem como o cercamento de toda área e um sistema de irrigação que lhes permita cultivar a terra independente das condições do tempo (Entrevistado 10). 
Um exemplo é a afirmação de um entrevistado:

Uma casa própria com conforto. Imagino muito legal, com uma propriedade com muito valor (Entrevistado 15). aconteça?"

$\mathrm{E}$, nesse momento ocorreu a pergunta: "O que é preciso para que isso

As respostas reiteraram todas as constatações oriundas de todo 0 desenvolvimento dos relatos:

força de vontade, trabalho e crédito financeiro, limpeza do açude para ter água, árvores, comida para os bichos como o milho, vaca de leite, ter água e luz(Entrevistado 6).

A motivação dos entrevistados encontra amparo nas observações de Aleixo (2007, p.4), ao se referir que a constituição dos assentamentos rurais traz no imaginário uma certa dose de idealização projetando que em havendo necessidades de mudanças, as mesmas serão insignificantes, pois esta, em ocorrendo representará uma fase após a conquista da terra.

Assim, observa-se a necessidade de técnicas levando-se em conta as situações impostas, os recursos disponíveis e as diferentes realidades sociais e econômicas para reduzir as distorções, as desigualdades e criar locais complexos em "lugares" com nova história.

\section{CONSIDERAÇÕES FINAIS}

Tendo como base o convívio e o diálogo, procurou-se neste estudo caracterizar as condições físicas dos lotes recebidos pelas famílias do Assentamento Itaguaçú e as melhorias decorrentes da organização e ocupação destes locais, bem como atendeu outro objetivo proposto de analisar a projeção futura através da manifestação de seu imaginário.

A concepção dos assentados, embora traduzida de forma singela, demonstrou a preocupação em se efetivar na terra e buscar rendimentos para a sobrevivência individual e de grupo o que demonstra noções de união, solidariedade e laços de afinidade.

Elementos presentes na prática rural como as plantações e a criação de animais, bem como, a presença de estruturas básicas, como o solo, a água e a cobertura vegetal foram enaltecidas expressando as possibilidades de uso dos recursos naturais para seu sustento e, como espaços de produção.

A percepção da importância das árvores não somente como elemento fornecedor de alimentos e madeira, mas também como fonte de sombra e de abrigo bem como de elemento de configuração da paisagem transpareceu nas respostas comprovando o estabelecimento de relações com o ambiente natural e propondo a inclusão do vegetal no cotidiano da comunidade.

Evidenciou-se nessa pesquisa que deve haver uma correlação entre conhecimentos teóricos e práticos a fim de auxiliar estes iniciantes nas técnicas agrícolas a buscar maior satisfação tanto na produção, como na fixação dos mesmos no meio rural estabelecendo espaços de experiências e trocas no universo de habilidades de cada sujeito.

Ressalta-se a necessidade de participação da Extensão Rural em assentamentos que deve ocorrer de forma interdisciplinar, dada às diferenças nas necessidades e anseios desta população, pois o somatório de condicionantes como 
a falta de infraestrutura e desconhecimento técnico pode implicar, futuramente, e de forma negativa, na realidade do local.

A experiência da pesquisa confirmou o verdadeiro papel da extensão rural como agente nas mudanças sonhadas e desejadas pelos cidadãos que vivem no meio rural, totalmente ausente no caso do Assentamento Itaguaçu no município de São Gabriel - RS, onde famílias buscam além de seus interesses básicos, o desenvolvimento e a sustentabilidade.

\section{REFERÊNCIAS}

ALEIXO, D. N. S. Mudanças de beneficiários e formas de reocupação de lotes no Assentamento Capelinha, Conceição de Macabu, RJ. 2007.199 p. Dissertação (Mestrado em Ciências). Instituto de Ciências Humanas e Sociais. Curso de PósGraduação de Ciências Sociais em Desenvolvimento, Agricultura e Sociedade. Universidade Federal Rural do Rio de Janeiro, RJ, 2007.

ARANA, A. R. A.; ALMIRANTE, M. F. A importância do corredor ecológico: um estudo sobre Parque Estadual "Morro do Diabo" em Teodoro Sampaio- SP. Geografia, v. 16, n. 1, p. 143-168, 2007.

BERGAMASCO, S. M. P. P.; NORDER, L. A. C. O que são assentamentos rurais? São Paulo: Brasiliense, 1996.

BERGAMASCO, S. M. P. P. A realidade dos assentamentos rurais por detrás dos números. Estudos Avançados, n. 11,v. 31, p. 37-49, 1997.

BERGAMASCO, S. M. P. P. et al. Por um atlas dos assentamentos brasileiros: espaços de pesquisa. Rio de Janeiro: DL/Brasil, 1997.p. 51p.

BRASIL. Conselho escolar e a educação do campo. Brasília: Ministério da Educação, Secretaria de Educação Básica, 2006. p. 91.

BRASIL. Lei $\mathrm{n}^{\circ}$ 8.629, de 25 de fevereiro de 1993. Regulamenta os dispositivos constitucionais relativos à reforma agrária. Brasília, 25 fev.1993. Disponível em: <http://www.planalto.gov.br/ccivil_03/Constituicao>. Acesso em: 27 dez. 2012.

BRASIL. Decreto nำ1.110, de 9 de julho de 1970. Criação do INCRA. Brasília, 9 de jul.1970. Disponível em: <http://www010.dataprev.gov.br/sislex/paginas/24/1970/1110.htm>. Acesso em 09 jan. 2013.

CAMPOS, W. P.; SILVEIRA, M. A.; CALIARI, M. A pluriatividade e seu efeito sobre os agricultores familiares do Assentamento São Domingos dos Olhos D`Água Morrinhos GO Brasil. Extensão Rural, Santa Maria, v. 22, n. 1, p.36- 55, jan./mar. 2015.

CAPORAL. F. R. Bases para uma política nacional de formação de extensionistas rurais. Brasília -DT: [s.n.], 2009.

CARVALHO, H. M. Interação social e as possibilidades de coesão e de identidade sociais no cotidiano da vida social dos trabalhadores rurais nas áreas oficiais de reforma agrária no brasil. Curitiba, PR: NEAD, 1999. 
CRESPO, A. A. Estatística fácil. 14. ed. São Paulo: Saraiva, 1996.

CRUZ, N. N. D.; SANTOS, R. J. O desafio da permanência na terra: comercialização de posses e reprodução dos modos de vida nos assentamentos da reforma agrária do Triangulo Mineiro. Campo-território: Revista de Geografia Agrária. v. 6, n.11, p.249-279, 2011.

FAGOTTI, L. N. Rádios livres nas comunidades rurais dos assentamentos de Reforma Agrária do município de Araraquara. Revista Espaço de Diálogo e Desconexão, Araraquara, v. 5, n. 1, jul./dez. 2012.

FIETZ, V. R. et al. Condições socioeconômicas, demográficas e estado nutricional de adultos e idosos moradores em assentamento rural em Mato Grosso do Sul, MS. Segurança Alimentar e Nutricional, Campinas, v. 17, n. 1, p. 73-82, 2010.

FREIRE, P. Extensão ou comunicação? 11 ed. Rio de Janeiro: Paz e Terra, 2001. p. 93.

GOLDENBERG, M. A arte de pesquisar: como fazer pesquisa. 10 ed. Rio de Janeiro: Record, 2007.

GOVERNO DO ESTADO DO RIO GRANDE DO SUL-NÚCLEO REGIONAL DE INTEGRAÇÃO DA FAIXA DE FRONTEIRA. Plano de desenvolvimento e integração da faixa de fronteira do estado do Rio Grande do Sul. Porto Alegre: PDIF/ RS, 2012.

IBGE. 2010. São Gabriel. Disponível em: <http://www.ibge.gov.br/cidadesat/topwindow.htm?1>. Acesso em: 01 jan. 2013.

INSTITUTO NACIONAL DE COLONIZAÇÃO E REFORMA AGRÁRIA - INCRA. Pesquisa confirma que reforma agrária é um instrumento de combate à pobreza. Jornal. Publicação Especial do INCRA, ano 1, n. 2. Dezembro, 2010.

INCRA. 2011. Disponível em: <http://www.incra.gov.br>. Acesso em 27 dez. 2012.

MANICA, I. et al. Pomar doméstico- caseiro- familiar. Porto Alegre: Cinco Continentes, 2007. p. 112.

MARTINS, V.S. et al. Trajetórias do lugar de viver em terra de reforma agrária. Retratos de Assentamentos, Araraquara, v. 14, n. 1, p. 69-92, 2011.

MASCARO, L.; MASCARÓ, J. Vegetação urbana. 2 ed. Porto Alegre: Editora Venus, 2005. p. 203.

MELLO, L. P.; SULZBACHER, A. W. Os planos nacionais de reforma agrária no Brasil: a letargia de um desenvolvimento alternativo para o campo. In: XIV ENCUENTRO DE GEÓGRAFOS DE AMÉRICA LATINA: Reencuentro de Saberes territoriales latino-americanos. Anais... Lima, Perú, 2013.

MILANO, M.; DALCIN, E. Arborização de vias públicas. Rio de Janeiro: Light, 2000. p. 226. 
MIRALHA, W. Questão agrária brasileira: origem, necessidade e perspectivas de reforma hoje. Nera, Presidente Prudente, n. 8, jan./jun. p.151-172, 2006.

MONTOYA, L. J. et al. .Aspectos de arborização de pastagens e viabilidade técnicaeconômica da alternativa silvipastoril. In: SEMINARIO SOBRE SISTEMAS AGROFLORESTAIS NA REGIÃO SUL DO BRASIL, 1, Anais... Colombo. Colombo: Embrapa-CNPF, 1994, p. 157-172.

NAVARRO, A.C. Política agrícola: desenvolvimento e extensão rural. Brasília. Departamento Assistência Técnica e Extensão Rural, 1999. p. 18.

NEVES, J. L. Pesquisa qualitativa: características, usos e possibilidades. Cadernos de Pesquisas em Administração. v. 1, n. 3, 1996.

OLIVEIRA, M. L. O. Retratos de assentamentos: Um estudo de caso em assentamentos rurais formados por migrantes na região do entorno do Distrito Federal. 2007. Tese. 190f. (Doutorado em Desenvolvimento, Agricultura e Sociedade) - Universidade Federal Rural do Rio de Janeiro, Instituto de Ciências Humanas e Sociais. 2007.

PREFEITURA MUNICIPAL DE SÃO GABRIEL. Plano Diretor de Desenvolvimento Urbano e Ambiental de São Gabriel - Plano Estratégico. v. 1. 2008.

RAMALHO, C. B. Impactos socioterritoriais dos assentamentos rurais no município de Mirante do Paranapanema - região do Pontal do Paranapanema SP. Presidente Prudente: FCT/UNESP, 2002.

RAMIRES, G. M. et al. A organização do espaço produtivo no assentamento Sumaré I. Disponível em: <www.sober.org.br/palestra/2/973>. Acesso em 19 abr. 2013.

RANGEL, H. M. M. V.; SILVA, J.V. O direito fundamental à moradia comomínimo existencial, e a sua efetivação à luz do estatuto da cidade. Veredas do Direito, Belo Horizonte, v.6, n. 12, p.57-78, 2009.

RANIERI, S. B. L. Retrospecto da reforma agrária no mundo e no Brasil. In: SPAROVEK, G. A qualidade dos assentamentos da reforma agrária brasileira. São Paulo: Páginas \& Letras Editora e Gráfica, 2003. p.5-37.

REFORMA AGRÁRIA NO BRASIL. Disponível em: <reforma-agraria-no brasil.info>. Acesso em 15 ago. 2014.

RODRIGUES, E. R. et al. Viveiros "Agroflorestais" em assentamentos de reforma agrária como instrumentos de recuperação ambiental: um estudo de caso no Pontal do Paranapanema. Caderno Biodiversidade, v. 4, n. 2, p. 1-8, 2004.

SANTALUCIA, M.; HEGEDUS, P. Cooperativismo e assentamento rural na percepção do uso coletivo e individual da terra mediante metodologia q: o caso de Charqueadas. Extensão Rural, Santa Maria, Ano XII, jan./dez. p.97-128, 2005. 
SILVA, V. P.et al.Sombras e ventos em sistema silvipastoril no noroeste do Estado do Paraná. In: CONGRESSO BRASILEIRO EM SISTEMAS AGROFLORESTAIS, 2. Belém, Anais....Belém: Embrapa/CPATU, 1998, (Volume de Resumos).

SILVA, A. G.; ARAUJO, J. P. O dilema da assessoria em assentamentos rurais: entre o ideal concebido e o real praticado. Extensão Rural, Santa Maria, Ano XV, p.103$127,2008$.

SILVA, A. W. L. Identificando e superando dificuldades na relação cognitiva entre técnico e produtor rural: uma abordagem baseada na "biologia do conhecer". Extensão Rural, Santa Maria, v. 20, n. 1, jan./mar. p.37-55, 2014.

SOUZA, L. R.; PEREIRA, F. S. Problematização da reforma agrária como política social no Brasil em anos recentes. In: CONGRESSO DA SOCIEDADE BRASILEIRA DE ECONOMIA, ADMINISTRAÇÃO E SOCIOLOGIA RURAL, XLVI. Anais... Rio Branco, Acre, 2008.

SPAROVEK, G.; MAULE, R. F. Perspectivas da definição da qualidade dos assentamentos. In: SPAROVEK, G. A qualidade dos assentamentos da reforma agrária brasileira. São Paulo: Páginas \& Letras Editora e Gráfica, 2003. p. 163-164.

STRACHULSKI, J.; FLORIANI, N. Formação do sistema agrário na região do Paraná tradicional: um estudo de caso da comunidade rural Linha Criciumal em Cândido de Abreu. Extensão Rural, Santa Maria, v.21, n.3, jul./set. p.146- 174, 2014.

TRIVIÑOS, A. S. Introdução à pesquisa em ciências sociais: a pesquisa qualitativa em educação. São Paulo: Atlas, 1987.

TSUKAMOTO, R. Y.; ASARI, A. Y. Assentamentos rurais e agricultura familiar: processo de territorialização e perspectivas de auto-sustentação. Geografia. v. 12, n. 1, p.484-494, jan./jun. 2003.

TURNES, V. A. Sistema Delos: indicadores para processos de desenvolvimento local sustentável. 2004. 227 f. Tese (Doutorado em Engenharia de Produção) Programa de Pós-Graduação em Engenharia de Produção, UFSC/ Florianópolis.

VOLPE, C. A.; SCHÖFFEL, E. R. Quebra-ventos. In: RUGGIERO, C. Bananicultura. Jaboticabal: FUNEP, 2001. p. 196-211.

XAVIER, M. S. A educação popular do campo e a realidade camponesa. Disponível em: <www.anped.org.br/reunioes/30ra/trabalhos/GT06-3377-Int.pdf> Acesso em 19 abr. 2013. 